\title{
Editorial announcement regarding title change of Chinese Journal of Cancer to Cancer Communications
}

\author{
Rui-Hua Xu*
}

On behalf of the editorial board, I am pleased to announce the title change of Chinese Journal of Cancer (Chin J Cancer, CJC; eISSN, 1944-446X) to Cancer Communications (Cancer Commun, CC; eISSN, 2523-3548). From March 2018, the journal will be published under the new title Cancer Communications with the same scope of publication as the former title. CJC was launched in 2010 as the official journal of the Chinese Anti-Cancer Association (CACA) and the US Chinese Anti-Cancer Association (USCACA). Under its new name, Cancer Communications continues to be sponsored by Sun Yatsen University Cancer Center [1]. Cancer Communications, like its predecessor $C J C$ has been since 2014, will be indexed in Medline/PubMed, PubMed Central, Directory of Open Access Journals (DOAJ), Scopus, the Western Pacific Region Index Medicus, CA, and Science Citation Index Expanded (SCIE) continuously.

With an international editorial board and science editors, our journal will continue to publish peer-reviewed, open access, and English-language scientific articles in the areas of basic, clinical, and translational cancer research that aim to improve human health through understanding cancer, preventing cancer onset, reducing cancer mortality, and improving the quality of life of cancer survivors worldwide [2]. Our journal emphasizes timely cancer issues, and under its previous title has published several thematic series such as air pollution and cancer [3], tumor metastasis [4], tumor angiogenesis [5], gastric cancer [6], and the 150 most important questions in cancer research and clinical oncology [7], among others.

The impact of CJC in the international arena has been steadily increasing. We are very pleased to see that the historical impact of $C J C$ has been markedly augmented in the world. The Journal Citation Report (JCR) Impact Factor (IF) of CJC increased from 2.814 in 2015 to 4.111 in 2016.

*Correspondence: xurh@sysucc.org.cn

Sun Yat-sen University Cancer Center, Guangzhou 510060, China
We are grateful to all the editorial board members from all over the world for their contributions toward improving the journal and in selecting the new journal title. We especially want to thank all of our authors for contributing their wonderful work and all the reviewers for their professional and thoughtful input in helping the journal to achieve its high standards.

The new title, Cancer Communications, is a new beginning. I hope that Cancer Communications will continue to make fundamental contributions to the field of cancer research and help to strengthen communication and collaboration among oncology researchers all over the world.

\author{
Authors' contributions \\ The author read and approved the final manuscript. \\ Competing interests \\ The author declares that he has no competing interests. \\ Ethics approval and consent to participate \\ Not applicable. \\ Received: 24 February 2018 Accepted: 6 March 2018 \\ Published online: 09 March 2018
}

References

1. Chinese Journal of Cancer. http://www.cjcsysu.cn/.

2. Zeng YX, Zhang W, Qian CN, Xu RH, Ruan J. The Chinese Journal of Cancer is indexed in Science Citation Index (SCl) expanded. Chin J Cancer. 2014;33(8):367-8.

3. Zhang W, Qian CN, Zeng YX. Air pollution: a smoking gun for cancer. Chin J Cancer. 2014;33(4):173-5. https://doi.org/10.5732/cjc.014.10034.

4. Qian CN, Mei Y, Zhang J. Cancer metastasis: issues and challenges. Chin J Cancer. 2017;36(1):38. https://doi.org/10.1186/s40880-017-0206-7.

5. Pezzella F, Gatter K, Qian CN. Twenty years after: the beautiful hypothesis and the ugly facts. Chin J Cancer. 2016;35:22. https://doi.org/10.1186/ s40880-016-0087-1.

6. Yan L. The journey of personalizing gastric cancer treatment. Chin J Cancer. 2016;35(1):84. https://doi.org/10.1186/s40880-016-0149-4.

7. Qian CN, Zhang W, Xu RH. Defeating cancer: the 150 most important questions in cancer research and clinical oncology. Chin J Cancer. 2016;35(1):104. https://doi.org/10.1186/s40880-016-0165-4. 